\title{
Time spent on provision of Antenatal Care and associated factors among public and private health facilities in Axum town, North Ethiopia: Comparative cross sectional study
}

Nigusse Gebremedhn Nerea

Tigray Regional Health Bureau

Haileselasie Berhane Alema ( $\sim$ haileselasieb@yahoo.com )

Aksum University

Mulubirhan Tirfe Tesfay

Aksum University

Research article

Keywords: Antenatal care, private health facilities, public health facilities, time spent

Posted Date: June 9th, 2020

DOI: https://doi.org/10.21203/rs.3.rs-29208/v1

License: (c) (i) This work is licensed under a Creative Commons Attribution 4.0 International License.

Read Full License 


\section{Abstract \\ Background}

In most developing countries the contact time among antenatal care attendees and care providers have effects on quality of antenatal services and health outcomes. Effectiveness of focused antenatal care relies on standard time spent provisions. Hence this study evaluated the time spent and associated factors on provision of antenatal care in public and private health facilities in Axum Town, Northern Ethiopia.

\section{Methods}

Institutional based comparative cross-sectional mixed quantitative and qualitative methods were used. Data were collected through exit interviews from 456 antenatal care attendees. Qualitative data were also collected using an in-depth interview with providers. The collected data were entered using EPI info version 3.5.1 software then exported to SPSS version 21 software for analysis. Multivariate logistic regression model was used to identify determinant factors of time spent on antenatal care provision at $p$ value $<0.05$.

\section{Results}

Majority, 378 (84.8\%) of pregnant woman were served below the mean standard time in both public and private health facilities. The mean $( \pm S D)$ time spent for first antenatal care provision in private was 19.7 $( \pm 8.5)$ minutes, which is higher than public health facilities with mean time spent $( \pm S D)$ of $13.2( \pm 3.8)$ minutes. The mean time spent on antenatal care was significantly different in public and private health facilities. Factors that significantly affect time spent on provision of antenatal care were: type of health facilities $[A O R=2.60 ; 95 \% \mathrm{Cl}, 1.07-6.33]$, frequency of antenatal care visit $[\mathrm{AOR}=3.50 ; 95 \% \mathrm{Cl}, 1.92-6.36]$ and language similarity with provider $[\mathrm{AOR}=2.74 ; 95 \% \mathrm{Cl}, 1.23-6.12]$.

\section{Conclusions}

The mean time spent for first and revisit of ANC at both health facilities were lower than the WHO standards. Type of health facilities, frequency of antenatal care visit and language similarity with provider were predictors for time spent on ANC provision. Efforts should be targeted on standard provision of antenatal care.

\section{Background}

Among the various big pillars of safe motherhood initiatives, antenatal care (ANC) remains one of the essential interventions that have the potential to reduce maternal morbidity and mortality [1]. Despite the 
international emphasis in the last few years on the need to address the unmet health care needs of pregnant women and children progress in reducing maternal and child mortality, it is still a challenging agenda [2]. According to the Ethiopian Demographic and Health Survey (EDHS) 2011 report, the maternal mortality rate was 676 deaths per 100,000 live births [3].

World Health Organization (WHO) recommended strategies for safer motherhood health, one of this was the new four-visit focused antenatal care (FANC) model with standard time spent which would allow 30 to 40 minutes for a first visit and 20 minutes for a revisit. It has been highlighted that since the number of visits is reduced to four in the basic component a "standard contact time" (SCT), Standard contact time is the length of time that health providers will need if they follow protocol and carry out appropriate steps with clients) [4].

While many factors affect the quality of ANC services, an emerging body of literature suggest that the amount of provider's time spent with clients known as patient contact time (PCT) was a good proxy for quality and the basis for patients' positive outcomes and it was one of the determinants for uptake, satisfaction and continued utilization of ANC service [5]. A study conducted at public health clinics in Bangladesh on the factors affecting PCT showed that when one percent of patient service increase, the patient contact time reduced by $0.34 \%$. [6]. The study done in the Gambia on factors affecting ANC service offered at the public and private clinics showed that women at both health facilities (HF) did not receive sufficient information, education and communication with their healthcare providers about the services provided during ANC [7].

Despite the fact that time spent on ANC service was essential for the quality of service and improvement of maternal and child health, the knowledge about client-provider time spent on ANC is not well studied in Ethiopia in general and in Tigray Region in particular. Therefore, the aim of this study was to evaluate the time spent on the provision of ANC and to identify factors associated with time spent during the provision of ANC at public and private HF in Axum Town, Northern Ethiopia.

\section{Methods And Materials}

\section{Study setting}

Institution-based comparative cross-sectional mixed quantitative-qualitative study design was conducted to evaluate the magnitude and associated factors of time spent on the provision of ANC among public and private health institutions in Axum Town, Northern Ethiopia.

Axum town is one of the zones found in the region located about 235 kilometers from Mekelle, the capital of Tigray and $1011 \mathrm{~km}$ away from Addis Ababa, capital of Ethiopia. According to the Ethiopian National census report in 2007, the total population of Axum town was 56,576 [8]. The study was conducted in three public health facilities (HF) namely: Axum hospital, Axum health center and Millennium health center; and four private HF namely: Kaleb, Bazen, Tsion, and Senay higher clinics. Out of the total population of Axum town, 30,293 are females with a pregnancy rate of $3.4 \%$ and the annual ANC service 
coverage in the study area was 95\% [9]. The study was conducted from January 27 to April 1, 2015. All pregnant women attending in public and private HF for ANC service during data collection were included. Pregnant women who were critically ill were excluded from the study.

\section{Sample size and sampling technique}

The required sample size was calculated using a double-population proportion formula with the assumptions of $36 \%$ of pregnant women in public HF time spent were more than 30 minutes [10]. The proportion of time spent among pregnant women $>30$ minutes for provision of ANC were taken $50 \%$ in private HF due to lack of previous similar study and $14 \%$ significance difference was detected between public and private HF with a $95 \%$ confidence level, power of $80 \%$, and $1: 1$ ratio. The total sample size after adding a $10 \%$ non-response rate was 456 .

The study participants were selected based on proportional allocation based on the preliminary survey average number of ANC users in the most recent one month report from each health facility. Study subjects at each health facility were selected using systematic random sampling until the required sample size was achieved. The sampling interval $(k=3)$ was calculated by dividing the average number of ANC users in the most recent one month report from each Health facilities to the total sample size.

Qualitative part: from the owner and managers of the health facilities 10 interviewees were selected. Hence there were no emerging new idea (information saturated) was reached further exploring idea is not needed. The key informants were purposively selected because of either they are the owner of private health facility or the manager of the facility to get adequate and correct information.

\section{Data tools}

The quantitative questionnaire was adopted and structured from different literatures $[6,11,12]$. The questionnaire was initially prepared in English and then translated into local the language (Tigrigna) and back to English to check its consistency. Pretest was done in shire health facilities which are 60 kilometers away from the study area. Any question which was ambiguous and/or unclear was modified or removed based on the pretest results. The questionnaire included socio-demographic characteristics, staff commitment, health care related factors, client-provider communication, and knowledge on ANC service.

Time spent between provider \& clients was measured using stop watch monitoring, and open-ended interview guide using tape recorder (for provider's in-depth interview) and checklists for observational data (number of ANC attendants per day) were also used to collect the qualitative data (look at additional file). To observe the availability of standard services at both health facilities item sentences was developed. The items response was categorized on basis of their level of agreement on five-point scale ranging from "strongly disagree" to "strongly agree". The reliability of the items was checked by item 
correlation analysis. The results were reported using cronbach's alpha (a). The result for internal consistency of items was reported as cronbach alpha 0.67

\section{Data management and analysis}

Quantitative part: The collected data were entered, cleaned and analyzed using SPSS version 21 statistical software. Descriptive statistics such as mean \pm standard deviation, frequency and percentages were used to summarize the findings. Bivariable logistic regression model analysis was done to identify eligible variables at $p$-value $<0.05$. To control confounding effect those significant variables were included in multivariable logistic analysis to identify predictors of time spent among ANC mothers at pvalue less than 0.05 with $95 \% \mathrm{Cl}$. Finally t-test for significance difference in the mean time spent on ANC was assessed among public and private HF.

Qualitative data: The verbatim recorded information was analyzed; the Tigregna audio-recorded interviews were listened carefully and transcribed into texts. The transcribed data then translated into English language and back to Tigrigna to ensure consistency and accuracy of wording and authentic representation of the participant's information. Sorting of the emerging themes after we read and become familiar with the texts. Then, we developed themes and coded. Finally we read all transcripts, the codes of transcripts, if there is irrelevant information reduced unnecessary data. Lastly the themes were shared into meaningful data that was the interpretation.

\section{Data quality control}

\section{For quantitative data}

For qualitative data the interviewer prepared secure and silent environment for interviewing before interview has started and made ready logistic requirements to assure quality of data. Before they were standby for interview, the interviewer greets politely to set the environment friendly. Guiding questions were avoided.

\section{Results}

\section{Socio-demographic characteristics}

A total of 446 subjects were participated in this study with of $98 \%$ response rate. More than half 228 $(51.12 \%)$ of the participants were from public HF. The mean ( \pm SD) age of respondents in both HF was $27.8( \pm 5.2)$ years. Of those who served in public HF $38.6 \%$ was not attended formal education. The majority $(92.2 \%)$ of the respondents who visited private HF were from urban residents [Table 1]. 
Table 1

Socio-demographic characteristics of respondents among public and private health facilities, Axum town, north Ethiopia

\begin{tabular}{|c|c|c|c|c|c|}
\hline \multirow{2}{*}{$\begin{array}{l}\text { Socio-demographic } \\
\text { variables }\end{array}$} & \multirow{2}{*}{$\begin{array}{l}\text { Public-HF (N= } \\
228) \\
N(\%)\end{array}$} & \multirow{2}{*}{$\begin{array}{l}\text { Private-HF (N= } \\
218) \\
\mathrm{N}(\%)\end{array}$} & \multirow{2}{*}{$\begin{array}{l}\text { Total }(\mathrm{N}= \\
446) \\
\mathrm{N}(\%)\end{array}$} & \multicolumn{2}{|c|}{ Chi-square } \\
\hline & & & & $x^{2}$ & $\begin{array}{l}\text { p- } \\
\text { value }\end{array}$ \\
\hline \multicolumn{6}{|l|}{ Age (Years) } \\
\hline $15-24$ & $56(24.6)$ & $49(22.5)$ & $105(23.5)$ & 0.87 & 0.646 \\
\hline $25-34$ & $139(61)$ & $146(67)$ & $285(63.9)$ & & \\
\hline $35-49$ & $33(14.5)$ & $23(10.6)$ & $56(12.6)$ & & \\
\hline Mean $( \pm S D)$ years & $28.0 \pm 5.7$ & $27.7 \pm 4.7$ & $27.8 \pm 5.2$ & & \\
\hline \multicolumn{6}{|l|}{ Residence } \\
\hline Urban & $133(58.3)$ & $201(92.2)$ & 334 (74.9) & 6.02 & 0.014 \\
\hline Rural & $95(41.7)$ & $17(7.8)$ & $112(25.1)$ & & \\
\hline \multicolumn{6}{|l|}{ Education status } \\
\hline $\begin{array}{l}\text { Not attended formal } \\
\text { education }\end{array}$ & $88(38.6)$ & $19(8.7)$ & $107(24)$ & 4.03 & 0.045 \\
\hline Primary education(1 to 8 ) & $62(27.1)$ & $54(24.7)$ & $85(19.1)$ & & \\
\hline Secondary education & $50(2.9)$ & $79(36.2)$ & $129(28.9)$ & & \\
\hline Diploma \& above & $28(12.3)$ & $66(30.3)$ & $94(21.1)$ & & \\
\hline \multicolumn{6}{|l|}{ Marital status } \\
\hline Single & $9(3.9)$ & $4(1.8)$ & $13(2.9)$ & 0.39 & 0.942 \\
\hline Married & $219(96.1)$ & $214(98.2)$ & $433(97.1)$ & & \\
\hline \multicolumn{6}{|l|}{ Occupation } \\
\hline Student & $2(0.9)$ & $5(2.3)$ & $7(1.6)$ & 15.35 & 0.009 \\
\hline Merchant & $28(12.3)$ & $60(27.5)$ & $88(19.7)$ & & \\
\hline Governmental employee & $26(11.4)$ & $65(29.8)$ & $91(20.4)$ & & \\
\hline Farmer \& daily laborer & $99(43.9)$ & $17(7.8)$ & $115(26)$ & & \\
\hline House wife & $63(27.6)$ & $71(32.6)$ & $134(30)$ & & \\
\hline
\end{tabular}

* Indicates significant difference at $\mathrm{p}$-value $<0.05$

ETB $=$ Ethiopian Birr 


\begin{tabular}{|c|c|c|c|c|c|}
\hline \multirow{2}{*}{$\begin{array}{l}\text { Socio-demographic } \\
\text { variables }\end{array}$} & \multirow{2}{*}{$\begin{array}{l}\text { Public-HF }(\mathrm{N}= \\
228) \\
\mathrm{N}(\%)\end{array}$} & \multirow{2}{*}{$\begin{array}{l}\text { Private-HF }(\mathrm{N}= \\
218) \\
\mathrm{N}(\%)\end{array}$} & \multirow{2}{*}{$\begin{array}{l}\text { Total }(\mathrm{N}= \\
446) \\
\mathrm{N}(\%)\end{array}$} & \multicolumn{2}{|c|}{ Chi-square } \\
\hline & & & & $x^{2}$ & $\begin{array}{l}\mathrm{p}- \\
\text { value }\end{array}$ \\
\hline \multicolumn{6}{|c|}{ Estimated $\mathrm{H} / \mathrm{Hs}$ monthly income } \\
\hline$<500$ ETB & $56(24.6)$ & $37(17)$ & $93(20.9)$ & 2.19 & 0.534 \\
\hline 501 to 1500 ETB & $103(45.2)$ & $96(44)$ & $199(44.6)$ & & \\
\hline 1501 to 3500 ETB & $64(28.1)$ & $73(33.5)$ & $137(30.7)$ & & \\
\hline 3501 to 6000 ETB & $5(2.2)$ & $12(5.5)$ & $17(3.85)$ & & \\
\hline \multicolumn{6}{|c|}{ * Indicates significant difference at p-value $<0.05$} \\
\hline ETB $=$ Ethiopian Birr & & & & & \\
\hline
\end{tabular}

\section{Time spent on provision of ANC in public and private health institutions}

The mean $( \pm \mathrm{SD})$ time spent during first ANC visit at both HF was $17.1( \pm 7.7)$ minutes. At private HF the mean time spent for provision of ANC was $19.7( \pm 8.5)$ minutes where as $13.2( \pm 3.8)$ minutes in public HF. During revisit, the mean $( \pm S D)$ time spent in getting ANC at both HF was $10.3( \pm 5.5)$ minutes. The time spent during revisit ANC at private HF was $11.3( \pm 6.6)$ and $9.7( \pm 4.6)$ minutes in public HF.

The mean time spent on ANC provision was significantly different among public and private HF (t-test = $7.52, p<0.001)$. Mothers who served in private HF have higher time spent on care than those who were served in public HF. Similarly, the mean time spent on provision o ANC was significantly different in first visit and revisit ANC (t-test $=10.39$, $p$-value $<0.001)$. Mothers who first visited have higher time spent on care than who subsequently revisited.

\section{Level Of Satisfaction About Time Spent During Anc}

The mothers level of satisfaction about time spent on ANC with health care providers at public health facilities were: 62 (27.2\%) very satisfied, $134(58.8 \%)$ satisfied and, $32(14 \%)$ not satisfied. And the level of satisfaction in private health facilities were $122(56 \%)$, very satisfied, $74(33.9)$ satisfied and 22 $(10.1 \%)$ not satisfied.

\section{Variables Significantly Associated With Time Spent On Anc Provision}


On bivariate binary logestics regression analysis, variables found to be significantly associated with ime spent on provision of ANC were: residence, education level, occupation, type of HF (public versus private), maternal frequency of visit, provider sex, payment for ANC services and language similarity with health care providers.

After multivariable binary logistic regression was applied, variables significantly associated with time spent on ANC provision were: type of HF (public versus private), maternal frequency of visit and pregnant women speaks similar language with health care providers [Table 2]. 
Table 2

Variables associated with time spent on ANC provision in Axum public and private health facilities, Axum, North Ethiopia

\begin{tabular}{|lllll|}
\hline Variables & $\begin{array}{l}\text { Time spent on ANC } \\
\text { Standard Short }\end{array}$ & $\begin{array}{l}\text { Total }(\mathrm{N}= \\
446)\end{array}$ & COR (95\% Cl) & AOR (95\% Cl) \\
\hline
\end{tabular}

$$
N(\%) \quad N(\%) \quad N(\%)
$$

\section{Residence}

$\begin{array}{llllll}\text { Urban } & 59(13.2) & \begin{array}{l}275 \\ (61.7)\end{array} & 334(74.9) & \mathbf{2 . 4 6 ( 1 . 1 8 ,} & \begin{array}{l}0.79 \\ \mathbf{5 . 1 3})^{*}\end{array} \\ \text { Rural } & & & 0.22,2.83) \\ & 9(2.0) & \begin{array}{l}103 \\ (23.1)\end{array} & 112(25.1) & 1.00 & 1.00\end{array}$

\section{Educational status}

Not attended formal

education

$\begin{array}{ll}14(3.1) \quad 124 \\ & (27.8)\end{array}$

Attended formal

education

$54(12.1) \quad 254(57)$

$138(30.9) \quad 1.00$

1.00

\section{Occupation}

\begin{tabular}{|c|c|c|c|c|c|}
\hline Student & $1(0.2)$ & $6(1.3)$ & $7(1.6)$ & $\begin{array}{l}0.58(0.07 \\
4.99)\end{array}$ & $\begin{array}{l}0.36(0.04 \\
3.44)\end{array}$ \\
\hline Merchant & $18(4)$ & 70 (15.7) & $88(19.7)$ & $\begin{array}{l}0.89(0.46 \\
1.72)\end{array}$ & $\begin{array}{l}0.64(0.32, \\
1.31)\end{array}$ \\
\hline Employee & $9(2)$ & $82(18.4)$ & $91(20.40)$ & $\begin{array}{l}0.38(0.17 \\
0.85)^{*}\end{array}$ & $\begin{array}{l}0.27(0.11, \\
0.63)^{\star}\end{array}$ \\
\hline Farmer & $8(1.8)$ & $\begin{array}{l}107 \\
(24.0)\end{array}$ & $115(25.8)$ & $\begin{array}{l}0.26(0.11, \\
0.59)^{*}\end{array}$ & $\begin{array}{l}0.35 \\
(0.09,1.37)\end{array}$ \\
\hline Daily laborer & $2(0.4)$ & $9(2.0)$ & $11(2.5)$ & $\begin{array}{l}0.77(0.16, \\
3.76)\end{array}$ & $\begin{array}{l}1.51(0.2 \\
7.39)\end{array}$ \\
\hline House wife & $30(6.7)$ & $\begin{array}{l}104 \\
(23.3)\end{array}$ & $134(30.0)$ & 1.00 & 1.00 \\
\hline
\end{tabular}

Type of Health facilities providing antenatal care service

\begin{tabular}{|c|c|c|c|c|c|}
\hline Public-HF & $19(4.3)$ & $\begin{array}{l}209 \\
(46.9)\end{array}$ & $228(51.1)$ & 1.00 & 1.00 \\
\hline Private-HF & $49(11)$ & $\begin{array}{l}169 \\
(37.9)\end{array}$ & 218 (48.9) & $\begin{array}{l}3.19(1.81 \\
5.62)^{*}\end{array}$ & $\begin{array}{l}\text { 2.61 (1.07, } \\
6.33)^{\star}\end{array}$ \\
\hline
\end{tabular}

\section{Frequency of ANC visit}

1 st visit

$\begin{array}{ll}49(11.0) \quad & 151 \\ & (33.9)\end{array}$
$200(44.8)$
$3.88(2.20$,
$6.84)^{*}$

$1.16(0.51$,
$2.68)$

$\begin{array}{ll}\text { 1.88(1.01, } & 1.16(0.5 \\ 3.52)^{\star} & 2.68)\end{array}$ 


\begin{tabular}{|c|c|c|c|c|c|}
\hline \multirow{2}{*}{$\begin{array}{l}\text { Variables } \\
\text { Revisit }\end{array}$} & \multicolumn{2}{|c|}{$\begin{array}{l}\text { Time spent on ANC } \\
\text { Standard Short }\end{array}$} & \multirow{2}{*}{$\begin{array}{l}\text { Total }(\mathrm{N}= \\
\mathbf{4 4 6})\end{array}$} & \multirow{2}{*}{$\begin{array}{l}\text { COR }(95 \% \mathrm{Cl}) \\
1.00\end{array}$} & \multirow{2}{*}{$\begin{array}{l}\text { AOR }(95 \% \mathrm{Cl}) \\
1.00\end{array}$} \\
\hline & $19(4.3)$ & $\begin{array}{l}227 \\
(50.9)\end{array}$ & & & \\
\hline \multicolumn{6}{|c|}{ Provider sex for ANC care } \\
\hline Male & $46(0.31)$ & $\begin{array}{l}186 \\
(41.7)\end{array}$ & $232(52.0)$ & $\begin{array}{l}2.16(0.249 \\
3.73)^{*}\end{array}$ & $\begin{array}{l}0.69 \\
(0.29,1.66)\end{array}$ \\
\hline Female & $22(4.9)$ & $\begin{array}{l}192 \\
(430)\end{array}$ & $214(48.0)$ & 1.00 & 1.00 \\
\hline \multicolumn{6}{|c|}{ Payment for ANC service } \\
\hline Yes & $49(11.0)$ & $\begin{array}{l}169 \\
(37.9)\end{array}$ & $218(48.9)$ & $\begin{array}{l}3.19(1.81 \\
5.62)^{*}\end{array}$ & $\begin{array}{l}2.24(0.94 \\
5.30)\end{array}$ \\
\hline No & $19(4.3)$ & $\begin{array}{l}209 \\
(46.9)\end{array}$ & $228(51.1)$ & 1.00 & 1.00 \\
\hline \multicolumn{6}{|c|}{ Speak similar language with providers } \\
\hline Yes & $58(13.0)$ & $\begin{array}{l}235 \\
(52.7)\end{array}$ & $293(65.7)$ & $\begin{array}{l}3.53(1.75 \\
7.13)^{\star}\end{array}$ & $\begin{array}{l}2.74 \\
(1.23,6.12) *\end{array}$ \\
\hline No & $10(2.2)$ & $\begin{array}{l}143 \\
(32.1)\end{array}$ & $153(34.3)$ & 1.00 & 1.00 \\
\hline
\end{tabular}

Occupation of the pregnant mothers was strongly associated with time spent during ANC provision. Respondents who were governmental workers were $74 \%$ less likely to spent standard time than house wife $(\mathrm{AOR}=0.26 ;(95 \% \mathrm{Cl}, 0.11-0.63)]$.

Pregnant mothers who attended their ANC in private health facilities were 2.6 times more likely to spend expanded time with care provider than who attended in public HF $[A O R=2.61 ;(95 \% \mathrm{Cl}, 1.07-6.33)]$.

Participants who has first visit for ANC were 3.5 times more likely to spent standard time with healthcare provider as compared to those pregnant mothers in subsequent ANC visit [AOR $=3.50 ;(95 \% \mathrm{Cl}, 1.93-$ 6.37)].

Pregnant mothers who speak similar language with health care providers were 2.7 times more likely to spent longer time compared to who speaks different language [AOR $=2.74 ;(95 \% \mathrm{Cl}, 1.23-6.12)]$.

\section{Qualitative findings}

\section{In-depth interview with health care provider}


A total of ten health professionals (key-informants), one care provider from each service delivery points (six from public and four from private) and three the facility managers were included on the in-depth interview.

The three identified central themes that could be the reason for short time spent on care included: Health care provider's commitment, medical supplies related and social \& cultural belief of the mothers on antenatal care.

\section{Health care provider's commitment}

Health care provider expressed the reasons for short time spend with mothers during care were lack of inservice training, low staff motivation, low payments, shortages of workers, and large number of ANC

20-26 years from public health facility expressed his idea

"... the time spent with clients was short, this could be due to lack of refresher training about focused ANC components, e.g. still I have not taken any in-service training either from the government or nongovernmental organizations as a result of this, I am unable even to counsel or deliver the whole ANC component to the clients in other words omission of some services resulted in short client contact time."

Another 30-38 years from private health facility

“...for standard time spent, smart facial expression or good client provider relationship during history taking and physical examination is mandatory for pregnant women to initiating for asking and discussing their issue. He also reported low level qualification, lack of confidentiality and privacy are the main cause for short time spent. Knowledge and skill during history taking and physical examination is mandatory to deliver standard care on standard time. if pregnant mothers secured adequate confidential and privacy, they will more initiate for discussion their issue as a result spends enough time with us."

A 20-25 years from public hospital also expressed that

“...the time we spent for care to pregnant women was not enough because of poor administration and payment that causes de-motivation of staff. This de-motivation makes us to be negligence in providing the service based on focused ANC standards. Additionally, we forced to provide ANC service with limited man power to numerous attendants in limited time. So, to address all within the short working hours, we obligate to shorten each mothers contact time"

\section{Medical supplies or facilities}

Some health care providers also expressed their reasons on shorter time spent with provision of ANC.

20-27 years from public health center explained is idea as 
"... There is shortage and un-functional medical equipments like sphygmomanometer. And I was wondering here and there to find the functional equipment; as a result, I waste my working hours in finding rather than providing care with clients. As a result large number of pregnant mothers forced to wait me to get the service and I am hurrying in each client contact time to address all the clients which may the reason of short time spent on care."

\section{Social and cultural belief of the mothers}

Religious, area of residence and family care has own affect on the time spent during care.

30-40 years old care providers reasoned their experiences as:

"Pregnant mothers living in rural areas were less likely to be cooperative to discuss detail with health care provider about their health issue. This may be due to family poor communication and relation. Additionally, muslin-religious follower mothers are not cooperative to make physical examination due to their religious/cultural influence. As a result we prefer to omit some care and this may make short time spent with the mothers".

\section{Discussion}

The majority, 378 (84.8\%) of pregnant mothers have below the standard time spent on the provision of antenatal care in both public and private health facilities. The mean ( \pm SD) time spent in the first ANC provision for each mother in the private was $19.7( \pm 8.5)$ minutes, and $13.2( \pm 3.8)$ minutes in public health facilities.

The study revealed that type of HF (public or private), frequency of ANC visit and pregnant women who speak a similar language with health care providers were found to be significant predictors for time spent on provision of ANC.

Pregnant women who attended their antenatal care at public health facility were spent shorter time than those who attended at private HF. This result in line with studies done in the Gambia [7] in Pakistan [13] and comparative study from Tanzania, Kenya and Ghana [14]. The possible explanation for the time difference during Antenatal care in the facility could be; public health providers are less likely to be motivated by incentives compared to the private facilities. Health care providers at private facility have incentives which initiate to provide compassionate maternal caring service provision, short waiting times and standard cares to women. Additionally, this was also supported from the interview expressed that lack of incentive at public health facility make them low motivation.

Maternal frequency of ANC visit was predictor of time spent for provision of ANC. Pregnant women who visited first for antenatal care were more likely to spent longer time than revisited women. This finding was consistent with studies conducted in Burkina Faso, Uganda and Tanzania [5, 10, 15]. This can be explained that, health care providers failed to perform all standard procedures stipulated by WHO guideline. And some cares may be exempted in revisit and subsequent visit. 
Respondents who speak similar language with the health care provider during care have also a predictor variable for time spent on provision ANC. This result was inline with study done in USA [12]. This can be explained by the fact that a language difference with care provider was a barrier for effective communication. In the absence of effective communication the provision of standard maternal care will be limited and have short time spent with client.

\section{Limitation}

The limitation of this study might be that study participants from private health facilities have provided maternal care at evening. As a result study participants and the key informants were in hurry to get deep information. So, there might be information bias.

\section{Conclusion}

This study revealed that majority of pregnant women utilized ANC services shorter time spent at both health facilities. The mean time spent on provision of ANC at the public health facility was significantly shorter than the private HF. Type of HF care provided, frequency of ANC visit and pregnant women who speak similar language with health care providers were predictors of time spent for ANC provision. To provide quality of maternal care, efforts should be targeted at standard provision of ANC with adequate time spent to clients.

\section{Abbreviations}

ANC

Antenatal Care

EDHS

Ethiopian Demographic and Health Survey

FANC

Focused Antenatal Care

HF

Health Facility

OR

Odds Ratio

PCT

Patient Contact Time

SCT

Client Standard Contact Time

SD

Standard Deviation

SDPs

Service Delivery Points 
SPSS

Statistical Package for Social Sciences

WHO

World Health Organization

\section{Declarations}

Ethics approval and consent to participate

Ethical clearance was obtained from the Institutional Review Board (IRB) of College of Health Science, Mekelle University with reference number MU/CHS/RCS/215/2015. The letter of support was given from regional health bureau to respected health facilities. Respondents were given information about the objectives of the study and they have the right to participate or decline in the study and able to withdraw from the study at any time. Both written and verbal consent was obtained from the respondents before data collection. To keep confidentiality data was analysed anonymously.

Consent for publication

Not applicable

Availability of data and materials

Datasets obtained or analyzed during the current study are available from the corresponding author on reasonable request.

Competing interests

The authors have declared that no competing interests exist

Funding

The authors received no specific funding for this work

Authors' contribution

NGN: drafted the proposal. NGN, HBA and MTT: designed the study, conducted data analysis, interpretation of findings and manuscript preparation. All authors read and approved the final manuscript for publication.

Acknowledgement

We are very grateful to thank to our supervisor and data collectors. Moreover appreciation also goes to all the study participants. 


\section{References}

1. UNICEF, UNFPA and The World Bank

Organization WH. Trends in maternal mortality: 1990 to 2008. Estimates developed by WHO, UNICEF, UNFPA and The World Bank. Trends in maternal mortality: 1990 to 2008 Estimates developed by WHO, UNICEF, UNFPA and The World Bank 2010.

2. Abodunrin O, Bamidele J, Olugbenga-Bello A, Parakoyi D. Preferred choice of health facilities for healthcare among adult residents in Ilorin metropolis, Kwara state, Nigeria. International Journal of health research. 2010;3(2):79-86.

3. CSA I. Ethiopia demographic and health survey 2011. Addis Ababa, Ethiopia and Calverton, Maryland, USA: Central Statistical Agency and ICF International 2012, 430.

4. Organization WH. WHO antenatal care randomized trial: manual for the implementation of the new model. In. Geneva: World Health Organization; 2002.

5. Langer A, Villar J, Romero M, Nigenda G, Piaggio G, Kuchaisit C, Rojas G, Al-Osimi M, Belizán JM, Farnot U. Are women and providers satisfied with antenatal care? Views on a standard and a simplified, evidence-based model of care in four developing countries. BMC Womens Health. 2002;2(1):7.

6. Chao D, Nandakumar A, Barkat A, Avijit P. Factors Influencing Patient Contact Time at Public Health Clinics in Developing Countries: Evidence from Bangladesh. Geneva Health Forum Archive 2012.

7. Jallow IK, Chou Y-J, Liu T-L, Huang N. Women's perception of antenatal care services in public and private clinics in the Gambia. International journal for quality in health care. 2012;24(6):595-600.

8. Demographic E: Health survey 2011 central statistical agency Addis Ababa. Ethiopia ICF International Calverton, Maryland, USA 2012.

9. Axum. Woreda health office 2010 annual performance report.

10. Conrad P, Schmid G, Tientrebeogo J, Moses A, Kirenga S, Neuhann F, Müller O, Sarker M. Compliance with focused antenatal care services: do health workers in rural Burkina Faso, Uganda and Tanzania perform all ANC procedures? Tropical medicine international health. 2012;17(3):300-7.

11. Ozawa $S$, Walker DG. Comparison of trust in public vs private health care providers in rural Cambodia. Health policy planning. 2011;26(suppl_1):i20-9.

12. Schyve PM. Language differences as a barrier to quality and safety in health care: the Joint Commission perspective. J Gen Intern Med. 2007;22(2):360-1.

13. Mahar B, Kumar R, Rizvi N, Bahalkani HA, Haq M, Soomro J. Quantity and quality of information, education and communication during antenatal visit at private and public sector hospitals of Bahawalpur, Pakistan. Journal of Ayub Medical College Abbottabad. 2012;24(3-4):71-4.

14. Hutchinson PL, Do M, Agha S. Measuring client satisfaction and the quality of family planning services: a comparative analysis of public and private health facilities in Tanzania, Kenya and Ghana. BMC Health Serv Res. 2011;11(1):203. 
15. von Both C, Fleßa S, Makuwani A, Mpembeni R, Jahn A. How much time do health services spend on antenatal care? Implications for the introduction of the focused antenatal care model in Tanzania. BMC Pregnancy Childbirth. 2006;6(1):22.

\section{Supplementary Files}

This is a list of supplementary files associated with this preprint. Click to download.

- indepthinterview.docx 